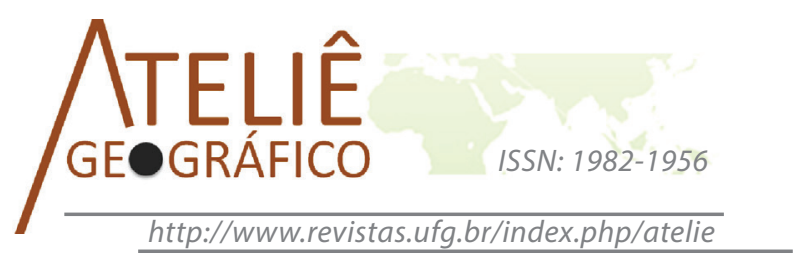

\title{
Breves apontamentos sobre a relação entre geografia e literatura
}

\author{
Brief notes about the relationship between geography and \\ literature
}

\section{Brèves notes sur la relation entre la géographie et littérature}

\author{
Melissa Anjos \\ Universidade do Estado do Rio de Janeiro \\ melanjos79@gmail.com
}

\begin{abstract}
Resumo
As pesquisas que a ciência geográfica vem desenvolvendo tem buscado inovar suas abordagens e dialogar com diferentes campos do conhecimento, entre eles o campo literário. Como resultado, tem produzido experiências que, entre outros enfoques, celebram as possibilidades de interseção entre ciência e arte. Desta maneira, a geografia tem criado possibilidades de leituras do universo vivido sob diferentes vieses, recortes, campos empíricos, metodologias e instrumentos teóricos. Assim, a compreensão do mundo a partir das tramas expostas pelos artistas (literatos) e fomentar uma leitura de mundo repleto de expressões existenciais se configura como um relevante caminho de entendimento a partir da inter-relação entre a linguagem científica e a artística. Dito isto, este artigo inicia uma discussão teórica acerca da relação entre ciência (geografia) e arte (literatura).
\end{abstract}

Palavras-chave: Geografia. Ciência. Arte. Literatura.

\begin{abstract}
The research that the geographical science has been developing has sought innovate its approaches and dialogue with different fields of knowledge, including the literary field. As a result, experiencesproduced, among other approaches, celebrate the possibilities of intersection between science and art. In this way, geography has created opportunities for readings the lived universe under different meanings, clippings, empirical fields, methodologies and theoretical instruments. Thus, the understanding of the world from plots exposed by artists (writers) and to foster a reading world filled with existential expressions is configured as an important path of understanding from the inter-relationship between the scientific and artistic
\end{abstract}


language. This paper begins a theoretical discussion about the relation between science (geography) and art (literature).

Keywords: Geography. Science. Art. Literature.

\begin{abstract}
Résumé
Les recherches développées par la science géographique ont innové leurs approches et le dialogue avec des différents domaines du savoir, entre eux, le champ littéraire. Comme résultat, il a produit des expériences que, entre autres approches, célèbrent les possibilités d'intersection entre la science et l'art. De cette façon, la géographie a créé des possibilités des lectures de l'univers vécu sous différents sens, découpage, champs empiriques, méthodes et outils théoriques. Ainsi, la compréhension du monde à partir des intrigues exposées par les artistes (écrivains) et de favoriser une lecture du monde plein des expressions existentielles est configuré comme un moyen important de compréhension de la relation entre la langue scientifique et artistique. Cela dit, cet article commence avec une discussion théorique sur la relation entre la science (géographie) et l'art (littérature).
\end{abstract}

Mots Clés: Géographie. Science. Art. Littérature.

\title{
Introdução
}

O mito, e depois a ficção, eram os encarregados de explicar os fenômenos ocorridos no mundo. Quando estes se tornam insuficientes, surge a ciência.Na proporção em que esta se sobressai, separa-se tanto do mito quanto da ficção e, para além do divórcio, inicia-se o combate a estes, configurando a luta da realidade contra o imaginário. Em fins do século dezenove, a crença na ciência era irrestrita, bem como a certeza da extinção dos mitos e suas explicações erráticas e supersticiosas acerca do mundo real. Existia, para Fiorin (1996, p. 9), a confiança de que "o estado positivo deixaria nas brumas da História os estados teológico e metafísico". Nos dias atuais, no entanto, "os mitos, depois de terem sido declarados mortos, estão bastante vivos. Nos subterrâneos, nutrem a ficção, a utopia e a ciência" (FIORIN, 1996, p. 9).

Neste ritmo, este artigo se propõe a iniciar uma discussão que não se pretende, de maneira alguma, profunda e determinante, acerca da relação entre ciência e arte - ou, para um melhor entendimento, entre geografia e literatura. Cabe ressaltar, não se trata de desmerecer, desmoralizar, descrer ou mesmo criticar a ciência, mas, tão-somente, reconhecer que a arte, aqui representada pela literatura, "(lugar por excelência de expressão dos mitos na modernidade), é uma forma tão boa de conhecimento quanto a ciência" (FIORIN, 1996, p. 9).

\section{Relação entre Ciência e Arte: um Caminho Possível}

Em sua etimologia a palavra ciência - do latim scienti \{conhecimento\} derivado do verbo scire \{saber\} -, refere-se, de modo abrangente, a qualquer conhecimento ou prática sistemática. Em um sentido mais restrito, o termo alude ao corpo de 
conhecimentos sistematizados adquiridos via observação, identificação, pesquisa e explicação de determinadas categorias de fenômenos e fatos formulados metódica e racionalmente. Isto é, ato de perceber ou compreender por meio da razão e/ou da experiência tendo por base o método científico. Em linhas gerais, a ciência é o esforço para descobrir e aumentar o conhecimento humano de como a realidade funciona.

Neste sentido, a ciência, além de ser intrínseca ao homem é eticamente complexa por ser inseparável do seu contexto histórico-social. Em retrospecto, a ciência moderna só pode emergir, segundo Morin (1999, p. 9),

na efervescência cultural da Renascença, na efervescência econômica, política e social do Ocidente europeu dos séculos 16 e 17. Desde então, ela se associou progressivamente à técnica, tornando-se tecnociência e, progressivamente, se introduziu no coração das universidades, das sociedades, das empresas, dos Estados, transformando-os e se deixando transformar, por sua vez, pelo que ela transformava.

Porém, mudanças paradigmáticas ruíram com a concepção clássica de ciência que, esperava-se, continuasse se metamorfoseando. $\mathrm{O}$ conceito de ciência herdado de séculos anteriores não é absoluto, tampouco eterno. Pelo contrário, ainda de acordo com Morin (1999, p. 10),

enquanto os físicos acreditavam, em 1900, que sua ciência suprema estivesse quase completa, essa mesma física começava uma nova aventura, arruinando seus dogmas. A pré-história das ciências não terminou no século 17. A idade pré-histórica da ciência ainda não está morta no fim do século 20. Mas em toda parte, cada vez mais, tende-se a ultrapassar, abrir, englobar as disciplinas... O pensamento deve tornar-se complexo.

Nestes termos, há mais de trezentos anos que o conhecimento científico demonstra suas virtudes de descoberta e de verificação relacionado a todos os outros ramos de conhecimento. O mesmo, desde o século passado trouxe, de maneira singular, uma excepcional evolução ao nosso saber. Hodiernamente, é possível "medir, pesar, analisar o Sol, avaliar o número de partículas que constituem nosso universo, decifrar a linguagem genética que informa e programa toda organização viva” (MORIN, 1999, p. 15). Entretanto, mesmo com todas as suas benesses, a ciência, cada vez mais, exibe dificuldades oriundas desse mesmo conhecimento que produz, acarretando, ao mesmo tempo, possibilidades de subjugação e de extermínio da humanidade. Assim, é necessário entender que a ciência não é 'boa' nem 'má', mas simplesmente ambivalente (MORIN, 1999).

Nestas circunstâncias, e considerando sua ambivalência, presenciou-se, no mundo contemporâneo, a um tipo de levante ante a postura cientificista. A civilização da ciência, da lei, da regra, da precisão é questionada, evidenciando o desejo de um reencontro mais autêntico com a natureza e com o homem, pois o governo técnicocientífico mostra "a incapacidade do progresso em resolver os problemas sociais", uma 
vez que a "ciência não é de modo algum eficaz para resolver as grandes questões éticas e sociopolíticas da humanidade” (FOUREZ, 1995, p. 165).

Desta maneira, compreender a ciência não é fundá-la dogmaticamente em qualquer dos princípios absoluto ou a priori que a filosofia da ciência nos tem fornecido desde Descartes. Ao contrário, trata-se de compreendê-la enquanto "prática social de conhecimento, uma tarefa que se vai cumprindo em diálogo com o mundo e que é afinal fundada nas vicissitudes, nas opressões e nas lutas que o compõem e a nós, acomodados ou revoltados" (SANTOS, B., 1989, p. 13). Destarte, a ciência é produto da história humana e está ligada a ela. “O próprio conteúdo da ciência surge como uma criação humana, por e para seres humanos" (FOUREZ, 1995, p. 173). Corroborando com essa ideia, Morin (1999, p. 20 - itálicos no original) salienta que a ciência está na essência da sociedade e "embora bastante distinta dessa sociedade, é inseparável dela, isso significa que todas as ciências, incluindo as físicas e biológicas, são sociais".

Em consonância, Dias de Deus (2004, p. 213) afirma que a ciência "é feita por seres humanos em sociedade e daí decorre, na verdade, tudo o mais. Se a ciência faz parte da sociedade, a crítica da ciência tem de fazer parte da crítica da sociedade" e, neste sentido, não parece que escasseiem conjunturas provocando desconforto e/ou indignação e produzindo inconformismos. Para tanto, "basta rever até que ponto as grandes promessas da modernidade permanecem incumpridas ou o seu cumprimento redundou em efeitos perversos" (SANTOS, B., 2001, p. 23), como, por exemplo, da domesticação da natureza em benefício comum da humanidade, de uma sociedade mais justa e livre, fundamentada na criação da riqueza tornada possível pela conversão da ciência em força produtiva e da paz perpétua baseada no comércio, na racionalização científica dos processos de decisão e das instituições (SANTOS, B., 1989, 2001). No entanto, deve-se refletir sobre a multidimensionalidade científica, pois seus efeitos não são simples nem para o melhor nem para o pior. Tal pensamento encontra respaldo na afirmação de Popper ([s/d] apud MORIN, 1999, p. 59):

a história das ciências, como a de todas as idéias humanas, é uma história de sonhos irresponsáveis, de teimosias e de erros. Porém, a ciência é uma das raras atividades humanas, talvez a única, na qual os erros são sistematicamente assinalados e, com o tempo, constantemente corrigidos.

A ciência é, além de uma construção da sociedade, uma produção cultural, uma vez que, por seu intermédio, os homens desenvolvem uma obra poética onde manifestam, desvendam ou descortinam o mundo no qual se inserem e do qual faz parte uma infinidade de saberes do científico ao senso comum, tais como os estudos religiosos, artísticos, esportivos, entre outros. Em conformidade, Boaventura Santos (2003, p. 8384) alega que

os pressupostos metafísicos, os sistemas de crenças, os juízos de valor não estão antes nem depois da explicação científica da natureza ou da sociedade. São parte integrante dessa mesma explicação. A ciência moderna não é a única explicação possível da realidade e não há sequer qualquer razão científica para 
a considerar melhor que as explicações alternativas da metafísica, da astrologia, da religião, da arte ou da poesia. A razão por que privilegiamos hoje uma forma de conhecimento presente na previsão e no controle dos fenómenos nada tem de científico. É um juízo de valor. A explicação científica dos fenómenos é a autojustificação da ciência enquanto fenómeno central da nossa contemporaneidade.

Assim, desde a década de 1970, há uma cobrança, para as ciências humanas, de uma produção de conhecimentos a partir da junção dos seres humanos com o mundo vivido identificando os indivíduos e grupos sociais que, cotidianamente, vivenciam a espacialidade e elaboram significados repletos de orientação e referencialização espacial ofertando possibilidades de entendimento e/ou compreensão da vida. Desta maneira, o conhecimento se pauta na superação das distinções familiares e óbvias que até pouco tempo era considerada insubstituível, tais como mente-matéria, observador-observado, coletivo-individual e objetivo-subjetivo (SANTOS, B., 2003). O relativo esgotamento destas dicotomias ecoou nas disciplinas científicas que se estabeleceram sobre elas. Cabe ressaltar, ainda segundo Boaventura Santos (2003, p. 64-65),

sempre houve ciências que se reconheceram mal nestas distinções e tanto que se tiveram de fracturar internamente para se lhes adequarem minimamente. Refiro-me à antropologia, à geografia e também à psicologia. Condensaramse nelas privilegiadamente as contradições da separação ciências naturais/ ciências sociais. Daí que, num período de transição entre paradigmas, seja particularmente importante, do ponto de vista epistemológico, observar o que se passa nessas ciências.

Nestes termos, a construção das ciências sociais caminha por duas vias: a primeira vinculada à epistemologia e à metodologia positivistas das ciências naturais e a segunda, de vocação anti-positivista, "caldeada numa tradição filosófica complexa, fenomenológica, interacionista, mito-simbólica, hermenêutica, existencialista, reivindicando a especificidade do estudo da sociedade" (SANTOS, B., 2003, p. 68). Nas últimas décadas a força da segunda vertente foi tamanha que a emergência do humano em contraposição a uma concepção da natureza começou a ser considerada ultrapassada pelas ciências naturais. Portanto, à medida que as "ciências naturais se aproximam das sociais estas se aproximam das humanidades. O sujeito, que a ciência moderna lançara na diáspora do conhecimento irracional, regressa investido da tarefa de fazer erguer sobre si uma nova ordem científica" (SANTOS, B., 2003, p. 69).

Neste contexto, se o papel da ciência humana é desvendar o cotidiano que o homem, em seu dia-a-dia, confere significados, devemos procurar outras possibilidades de construção de tal riqueza, pois "uma das preocupações atuais é afastar a ciência de sua excessiva pretensão e admitir a arte como indicador cultural de grande capacidadede revelação de sentidos e capaz de apresentar sinais de sintonia com a ciência"(MONTEIRO, 2005 , p. 11). Atualmente, a criação científica pode ser aceita como próxima da criação literária ou artística, uma vez que a "arte apenas procura ilustrar o que a ciência expressa imediatamente sob a forma de conceito" porque "à semelhança destas pretende que a dimensão activa da transformação do real (o escultor trabalha a pedra) seja subordinada à 
contemplação do resultado (a obra de arte)" (STEINER, 1998, p. 27). O discurso científico, por seu turno, "aproxima-se cada vez mais do discurso da crítica literária", pois de algum modo esta "anuncia a subversão da relação sujeito/objecto" (SANTOS, B., 2003, p. 87). Para isso, as produções artísticas nos fornecem elementos distintos de compreensão do mundo vivido a partir da análise das possíveis expressões oriundas dos modos de entendimento dos artistas. Nesta conjuntura, o próprio catedrático Boaventura Santos (2003) estabelece uma ponte da ciência voltada para novos horizontes como, igualmente, se debruça sobre filosofias do significado, tais como a fenomenologia e a hermenêutica em meio a um mundo pleno de símbolos e significados que permitem a contemplação do outro nos estudos acadêmicos, uma vez que "é inegável que o pensamento e a conduta simbólica estão entre os traços mais característicos da vida humana e todo o progresso da cultura está baseado nestas condições" (CASSIRER, 1963, p. 50).

A referência ao universo simbólico aponta para a questão do símbolo. Este contém ou contempla algo de maior expressão e/ou valor e, uma vez que seu significado é atribuído pelo indivíduo ou grupo social, "qualquer elemento da natureza, artefato criado pelo homem, algo concebido no imaginário ou mesmo a cidade e a pátria podem se revestir de valores simbólicos" (SILVA, 2007, p. 45). Desta maneira, o homem encontrase submergido em uma orbe simbólica do qual integram elementos essenciais a sua identidade, tais quais a fé, a língua, a tradição mitológica, a ciência e a arte (DORFLES, 1992).

Por seu turno, etimologicamente, arte - do latim ars \{técnica e/ou habilidade \} -é comumente entendida como a atividade humana ligada a manifestações de ordem estética realizadas a partir de apreensões, emoções e ideias, com o objetivo de estimular essas instâncias de consciência nos espectadores, produzindo um significado único e diferente para cada obra. Isso ocorre porque a "obra de arte tem sempre significação estética (não confundir com valor estético): quer sirva ou não a um fim prático e quer seja boa ou má, o tipo de experiência que ela requer é sempre estético" (PANOFSKY, 2009, p. 30 - itálico no original). "A necessidade da arte é tão antiga como a própria humanidade" (STEINER, 1998, p. 12). No decurso tempo, o papel da arte tem sido considerado como um meio de reproduzir o vivido, adornar o dia-a-dia, bem como narrar e esclarecer a história e auxiliar na exploração do mundo e do próprio ser, atribuindo, a esta, "alta importância para o progresso cultural dos homens" (STEINER, 1998, p. 21).

Nestas circunstâncias, ao perfilar novas posturas da ciência, filosofia e arte, deixase de entender a ciência tradicional como "veículo único da verdade" (LOWENTHAL, 1985, p. 18), reinventando uma geografia aberta "à literatura e à arte" (FRÉMONT, 1980 , p. 262) e a capacidade de reflexão artística/crítica do geógrafo. Evidentemente, a ideia não encontrava coro afinado na academia, no entanto, "a investigação científica, a filosofia e a sensibilidade da arte não são inevitavelmente opostas" (MELLO, 2000, p. 149). De qualquer modo, como defendem Buttimer (1983) e Mello (2000), o estoque de conhecimento geográfico não está confinado a educação formal "derivando, igualmente, dos ecos da arte, assim como da poesia, afora outros canais de expressão" (MELLO, 2000, p. 149). 
A arte, bem como "todas as produções culturais são objetos de análises com pretensões científicas” (BOURDIEU, 2004, p. 19). Enquanto ação produtiva do homem, é um fenômeno social e parte da cultura. Está relacionada com a totalidade da existência humana, mantendo estreitas conexões com o processo histórico e possui sua própria história, conduzida por tendências que nascem, se desenvolvem e se metamorfoseiam. Foco de convergência de valores religiosos, éticos, sociais e políticos, a arte vincula-se “à religião, à moral e à sociedade como um todo, suscitando problemas de valor, tanto no âmbito da vida coletiva como no da existência individual, seja esta a do artista que cria a obra de arte, seja a do contemplador que sente os seus efeitos" (NUNES, 1991, p. 15).

Mas o que é arte? Para que serve? O que constitui sua essência? Ao longo da história da humanidade essas e outras questões foram, são e continuarão em pauta buscando uma resposta única e aceitável por todos. No entanto, longe de ser dependente da sociedade, faz-se mister entender que a atividade artística não encontra terreno na efetivação de funções pragmáticas e materiais, sejam elas de caráter "propagandísticopedagógico, político-social ou mesmo formal-hedonística". O que, embora importante, não condiciona o "impulso original de uma atividade que desde o início parece ter sido peculiar ao homem como uma característica necessária”, uma vez que (BAUMGART, 1994, p. 1-2)

desde a pré-história a atividade artística servia à interpretação do mundo e do homem no mundo. O primeiro legado da humanidade depois das ferramentas mais simples, antes que houvesse arquitetura, música, literatura etc., foram pinturas e esculturas. Com elas inicia-se a história da humanidade propriamente dita e a história da arte.

Pode-se estabelecer, então, que os artistas são tão importantes para a civilização humana quanto os cientistas, os filósofos, os políticos e os grandes líderes, porque a arte é uma necessidade básica, quase como precisar comer e dormir. Uma necessidade espiritual como a religião, porque fala aos nossos sentimentos e à nossa imaginação. E, ainda, porque satisfaz a carência de beleza sentida por todos. Os artistas são dotados de aptidões que promovem a comunicação de emoções e anseios aos outros mortais ou, como melhor sugere Steiner (1998, p. 34), eles se apresentam como o

continuador do espírito que atua no mundo; ele continua a Criação onde o espírito divino a abandonou. Ele apresenta a arte como a continuação livre da evolução natural. Com isto o artista se eleva acima da vida real comum e leva consigo quem consegue aprofundar-se em suas obras. Ele não produz para o mundo finito; ele o transcende.

Ora, essa produção da transcendentalidade só é possível porque a arte é, antes de tudo, um fazer, um conjunto de atos pelos quais se altera a silhueta e se converte a matéria ofertada pela natureza e pela cultura. Em um sentido mais amplo, qualquer atividade humana, desde que conduzida regularmente a um fim, pode chamar-se artística. Para Platão, segundo Bosi (1995), exerce a arte tanto o músico com sua lira quanto o 
político manejando os cordéis do poder ou, no topo da escala dos valores, o filósofo que desmascara a eloquência perspicaz do sofista.

A ideia de arte estabelece um contexto de ação na cultura e ensina a interpretar suas imagens como registros e indicações da intenção do artista (CALDAS, 2008). Para Gombrich (1995, p. 93), "toda arte tem origem na mente humana, em nossas reações ao mundo mais que no mundo visível em si”, existindo a predominância tanto do individual como do sensível. De acordo com Cassirer (1998), a linguagem, o mito, a arte e a ciência são formas simbólicas que traduzem, de diferentes maneiras, segundo intenções e valores diversos, a atividade formadora do pensamento, que se apropria do mundo vivido, estruturando sentimentos e significados. "Na arte é a concreção, o inverso da abstração, que prevalece: é o singular, o particular, que se sobrepõe ao geral. Em vez da ordem lógica dos conceitos, deparamos com significações” (NUNES, 1991, p. 69). Deste modo, "a arte é reflexo da vida" (ORTEGA Y GASSET, 1991, p. 45).

No que concerne à interpretação da arte, uma das principais consiste em concebê-la como um sistema de sinais, ou seja, como uma linguagem. Esta, um meio de comunicação, "é o móvel que permite às almas fechadas transpor as fronteiras de seu isolamento para entrar em contato umas com as outras, compreender-se, comunicarse pelos mesmos símbolos e agir em harmonia" (BASTIDE, 1971, p. 184). Por conseguinte, na medida em que a arte é uma linguagem, também se torna um instrumento de solidariedade social, por ser mais "estreita que a da palavra falada, excedendo a intercomunicação entre indivíduos separados, para estabelecer uma interpenetração das almas, uma fusão parcial das consciências" (BASTIDE, 1971, p. 184).

Nestas circunstâncias, para uma tentativa de aproximação da pesquisa com a existência humana, a proposta do diálogo com o saber artístico torna-se importante a partir do momento em que se entende que um autor edifica a sua arte partindo das maneiras com que o mesmo usufruía do seu lugar vivido de determinado período. No caso da literatura, o artista expõe as situações com que experiencia o lugar e, a partir de tal, arquiteta as suas narrativas, ou, como melhor sublinha Lajolo (1982, p. 7-8),

a literatura não é um jogo, um passatempo, um produto anacrônico de uma sociedade dessorada, mas uma atividade artística que, sob multiformes modulações, tem exprimido e continua a exprimir, de modo inconfundível, a alegria e a angústia, as certezas e os enigmas do homem.

Este pensamento parte do princípio que a literatura é essencial à história do homem, não só para contá-la, mas, também, para preservá-la.

Dito isto, a literatura é um exercício de reflexão na qual o literato escreve e reflete acerca de sua espacialidade e dos modos - ideológico, cultural, político, econômico, entre outros - que a compõe, indagando, criticando ou fornecendo sugestões para a transformação desses mesmos modos que fazem parte da sociedade. Aceitando a literatura como uma manifestação das experiências espaciais cotidianas do autor, podese projetar um saber científico ou filosófico diferenciado, aproximando-o das ruas e das relações, produzindo, portanto, um conhecimento em que os indivíduos possam se 
identificar e mesmo tecerem analogias com as coisas do dia-a-dia (AMORA, 2006) "tal qual uma palmeira, uma sabiá ou uma banda que encontram em seus quintais ou em uma rua ou praça qualquer" (ANJOS, 2010, p. 5).

Neste contexto, das diferentes correntes da ciência geográfica, o viés humanista tem feito da literatura uma fonte constante de referência, uma vez que esta evoca a alma dos lugares, apreende e expõe a atuação do homem, bem como "o cotidiano, o transcendental, o exílio, as viagens festivas, a nostalgia, enfim, uma ampla gama de motivos, privações, humores e emoções" (MELLO, 1991, p. 58), pois a obra literária é fruto da sociedade, "uma construção cultural ou social, não sendo um meio passivo ou neutro de comunicação e sim uma janela sobre o mundo" (MELLO, 1991, p. 58), porque seu autor, para "expressar comprofundidade o caráter do lugar... precisa ser um deles (do lugar)" (MELLO, 1991, p. 58), ou como melhor sugere Heidegger (1967, p. 43), "o homem se essencializa, de tal sorte, que ele é o lugar". Assim, um dos motivos para se utilizar como fonte de pesquisa as artes literárias é a "visibilidade a experiências íntimas, inclusive às de lugar" (TUAN, 1983, p. 180) por ela fornecida. Portanto, por intermédio da literatura, somos agraciados por uma geografia mais próxima da realidade, um 'geografar' do cotidiano, "no qual o espaço é preenchido de materialidade e significado. Uma geografia que traz, para o território, cheiros, sons, texturas, cores, sentimentos, lembranças, tramas, dramas, sabores..." (OLIVEIRA, J. e BRANDÃO, 2009, p.231).

Entre as manifestações da vida social, nenhuma traduz tão enfaticamente seus traços como as artísticas e, entre elas, as literárias. E como prática social a literatura existe desde o surgimento da escrita e se desenvolveu com a invenção da imprensa. Evidentemente, os escritos literários mudaram ao longo dos séculos, transformando-se e adaptando-se ao contexto político-social de cada período. Mas, o que é literatura?

Etimologicamente, a palavra literatura é derivada do latim littera que traduz o termo grego "gramma, significando letra do alfabeto, ou caractere da escrita. O coletivo litterae, equivalente ao grego grammata, indica, primeiro, uma carta (epistula), e depois, por extensão, qualquer tipo de obra escrita, ou então, instrução, cultura" (BERNARDO, 1999, p. 155 - itálicos no original). A partir do século XVIII, segundo Bernardo (1999, p. 156), tal terminologia passa a significar, nas línguas ocidentais,

certo corpo heterogêneo de escritos, repositório de saberes tidos por relevantes para todos os homens. Com a automização e especialização das diversas ciências, este sentido se restringe às produções ficcionais e de poesia, embora ainda se use, concomitantemente, para designar outros conjuntos de escritos (por exemplo, "literatura jurídica").

Sem uma resposta definida, entende-se que a literatura constrói e é porta para vários mundos que nascem das diferentes leituras que dela se fazem. Alguns se assemelham com o nosso, onde, por exemplo, há pessoas que morrem de fome nas ruas, bem como de mundos diferentes, "onde vivem espíritos, anjos, energias e demônios" (LAJOLO, 2001, p. 10). A literatura traz para o nosso lado mundos prometidos pela ciência, com seres artificiais sofisticados e com seres naturais manipulados em laboratório. Há histórias 
com palavras e imagens e histórias só com imagens e esses mundos não se desfazem na "última página do livro, na última frase da canção, na última fala da representação nem na última tela do hipertexto" (LAJOLO, 2001, p. 44). Permanecem no leitor, incorporados como vivência, marcos da história de leitura de cada um.

O mundo representado na literatura - por mais simbólico que seja - nasce da experiência que o escritor tem de sua realidade histórico-social, uma vez que a vida e a cultura de seu lugar "cristalizam-se em toda sua vivacidade e riqueza" em suas obras, contribuindo para "preservar a especificidade e singularidade de uma época, por vezes até melhor que documentos, reportagens, filmes e vídeos” (FREITAG, 1997, p. 92). Isso porque os autores conseguem abordar os "diferentes planos da vida subjetiva e objetiva, reproduzir intuições e descrever cenários, resumir fatos e deter-se em detalhes, criar uma trama e recriar ambientes" (FREITAG, 1997, p. 92), ao mesmo tempo em que radiografam a sociedade e a psique de suas personagens. No entanto, o universo que autor e leitor compartilham, a partir da criação do primeiro e recriação do segundo, é um universo que corresponde a uma síntese do aqui e agora da leitura, ainda que não coincida com o do escritor, pois "não é só quem escreve que significa; quem lê também produz sentidos" (ORLANDI, 1996, p. 101).

Nestes termos, o desenho do espaço geográfico fornecido pela obra literária é uma construção resultante da interação entre o que é descrito pelo autor e a imagem espacial captada pelo leitor, segundo vivências e informações, na medida em que "o processo de compreensão de um texto certamente não exclui a articulação entre as várias linguagens que constituem o universo simbólico de cada um" (ORLANDI, 1996, p. 38). Desta maneira, na medida em que o texto constrói uma imagem do espaço de uma sociedade o mesmo pode desvendar articulações ideológicas de um momento histórico, evidenciar a relação natureza/sociedade e expressar valores e interesses que podem interferir na organização do espaço (BROSSEAU, 2007).

Assim, o discurso literário permite que o leitor percorra os “caminhos já galgados pelo escritor e representados em sua narrativa", bem como "desbravar muitos espaços, descortinar múltiplas paisagens, revisitar vários lugares, percorrer diversas sendas regionais e atravessar fronteiras, por mais inexoráveis que sejam, dos polissêmicos territórios" (ARAÚJO, 2006, p. 93-94), pois esta linguagem, segundo Wanderley (1998, p. 23), "torna-se mais apta para exprimir as relações espaciais, porque as utiliza como símbolos ou metáforas das outras relações do homem com o meio que o cerca". Vale ressaltar, os textos não podem ser vistos como meras cópias ou reproduções do mundo a que se referem, ao contrário, devem ser entendidos como produtos da criação humana, concebidos em conformidade com um referencial. Logo, a literatura torna-se um lugar privilegiado para a discussão de espaço e do lugar (BARCELLOS, 2006).

Diante disso, a diversidade cultural literária é um laboratório onde várias temáticas podem ser abordadas pela ciência geográfica, contribuindo, sobejamente, para o desenvolvimento de estudos contemplando a cultura e a sociedade em suas diversas maneiras de manifestação no espaço e/ou no lugar. Neste sentido, a arte literária se configura como um caminho de análise/leitura e interpretação/decodificação do mundo 
vivido e experienciado dos indivíduos e grupos sociais ao funcionar como um testemunho de diferentes períodos, bem como as informações derivadas das fotografias, gravuras, esculturas, filmes e mesmo a música, uma vez que, segundo Araújo (2006, p. 91),

nas linhas e entrelinhas do discurso literário é possível descortinar, sentir, visibilizar e ler narrativas que, permeadas por conteúdos da existência do autor, expressam histórias de amor e de ódio, de vida e de morte, de sucesso e de fracasso, enfim, de sonhos, de fábulas e de fantasias. Essas histórias, protagonizadas por sujeitos criados pelo próprio autor, são tecidas sob um substrato espacial.

\section{Para não Concluir...}

Como já mencionado, este artigo seguiu a trilha da interface entre ciência e arte ou, para um melhor entendimento, geografia e literatura, pois concorda-se com Nuñez (2010, p. 74) quando salienta que

a literatura é uma arte; a geografia, uma ciência. A primeira atende a prerrogativa estética, valorizando, sobretudo, a capacidade de modelação da realidade e a dialetização da verdade com tudo o que é afirmativo da subjetividade e da imaginação; a segunda considera a dialética entre homem e natureza, a interrelação entre o caráter factual dos lugares e a dimensão existencial que a eles se agrega.

Nestas circunstâncias, nos espaços e lugares da literatura, o escritor, utilizando os matizes do seu mundo vivido, pinta suas obras de arte literárias, usando eufemismos, hipérboles e metáforas, construindo, com dor e alegria, suas histórias; arquitetando, por intermédio da arte de narrar, suas representações; forjando, com os fios da memória e docotidiano local, regional e nacional, suas tramas literárias (ARAÚJO, 2006). Assim, a literatura, além de conceder possibilidades para os leitores apreenderem o cotidiano particular de uma determinada sociedade e cultura, oferece dispositivos que podem contribuir para a compreensão dos valores que o escritor atribui às suas descrições literárias, identificando o espaço em suas narrativas e captando o espírito ou a alma do lugar nas tramas de sua escrita.

Por fim, busca-se na literatura uma companheira de pesquisa, uma inspiração para a procura de uma geografia poética, de afetos e de pertencimentos, pois "na literatura está à geografia com seus espaços e lugares, suas paisagens, em seus diferentes modos de viver e sentir" (OLIVEIRA, J. e BRANDÃO, 2009, p. 229), porque a literatura oferece temáticas estimulantes para a investigação geográfica, colaborando com o aumento das possibilidades de estudos de uma ciência que, por sua etimologia, ambiciona construir uma escrita $\{$ grafia $\}$ da terra $\{$ geo $\}$. 


\section{Referências}

ANJOS, Melissa. Geografia e literatura: um exercício de reflexão. In: ENCONTRO NACIONAL DE GEÓGRAFOS, 16., 2010, Porto Alegre. Anais... Porto Alegre: [s/n], 2010, p. 1-10.

AMORA, Antônio Soares. Introdução à teoria literária. 13. Ed. São Paulo: Cultrix, 2006.

ARAÚJO, Marcos Antônio Alves de. Geografia e literatura: representações espaciais na tessitura romanesca de José Lins do Rego. Revista Sociedade e Território, Natal, v. 18, n. 1/2, p. 89-112, jan./dez., 2006.

BARCELLOS, Frederico Roza. Espaço e Lugar: o olhar geográfico machadiano sobre o Rio de Janeiro do final do século XIX e início do século XX. 2006. (Mestrado em Geografia) - Instituto de Geociências, Universidade Federal do Rio de Janeiro, Rio de Janeiro, 2006.

BASTIDE, Roger. Arte e sociedade. 2. Ed. São Paulo: Cia. Ed. Nacional/EdUSP, 1971.

BAUMGART, Fritz. Breve história da arte. São Paulo: Martins Fontes, 1994.

BERNARDO, Gustavo. O conceito de literatura. In: JOBIM, José Luís (org.). Introdução aos termos literários. Rio de Janeiro: EdUERJ, 1999, p. 135-169.

BOSI, Alfredo. Reflexões sobre a arte. 5. Ed. São Paulo: Ed. Ática, 1995. (Série 'Fundamentos')

BOURDIEU, Pierre. Os usos sociais da ciência: por uma sociologia clínica do campo científico. São Paulo: Editora UNESP, 2004.

BROSSEAU, Marc. O romance: outro sujeito para a geografia. In: CORREAA, Roberto Lobato; ROSENDAHL, Zeny (org.). Literatura, Música e Espaço. Rio de Janeiro: EdUERJ, 2007, p. 79-121.

BUTTIMER, Anne. The Practice of Geography. London: Longmans, 1983.

CALDAS, Waldenyr. Cultura. 5. Ed. São Paulo: Global Ed., 2008. (Coleção 'Para Entender)

CASSIRER, Ernst. Antropología filosófica: introducción a una filosofia de la cultura. 3. Ed. México: Fondo del Cultura Económica, 1963.

. Filosofia de las formas simbólicas: fenomenologia del reconocimiento. 2. Ed. México: Fondo del Cultura Económica, v. 3, 1998.

DIAS DE DEUS, Jorge. A minha crítica da ciência. In: SANTOS, Boaventura de Souza (org.). Conhecimento prudente para uma vida decente: "um discurso sobre as ciências" revisitado. São Paulo: Cortez Ed., 2004, p. 213-220.

DORFLES, Gillo. O devir das artes. São Paulo: Martins Fontes, 1992.

FIORIN, José Luiz. As astúcias da enunciação: as categorias de pessoa, espaço e tempo.

São Paulo: Ed. Ática, 1996. 
FOUREZ, Gérard. A construção das ciências: introdução à filosofia e à ética das ciências. São Paulo: Ed. UNESP, 1995.

FREITAG, Bárbara. Berlim: memória literária e futuro político. In: SCHIAVO, Cléia; ZETTEL, Jayme (coord.). Memória, cidade e cultura. Rio de Janeiro: EdUERJ, 1997, p. 91-109.

FRÉMONT, Armand. A região, espaço vivido. Coimbra: Livraria Almadina, 1980.

GOMBRICH, Ernest Hans. Arte e ilusão: um estudo da psicologia da representação pictórica. 3. Ed. São Paulo: Martins Fontes, 1995.

HEIDEGGER, Martin. Sôbre o humanismo. Rio de Janeiro: Edições Tempo Brasileiro LTDA., 1967.

LAJOLO, Marisa. O que é literatura? 2. Ed. São Paulo: Brasiliense, 1982.

. Literatura: leitores e leitura. São Paulo: Moderna, 2001.

LOWENTHAL, David. Geografia, experiência e imaginação: em direção a uma epistemologia geográfica. In: CHRISTOFOLETTI, Antônio (org.). Perspectivas da geografia. São Paulo: Difel, 1985, p. 103-141.

MELLO, João Baptista Ferreira de. O Rio de Janeiro dos compositores da música popular brasileira - 1928/1991 - uma introdução à Geografia Humanística. 1991. (Mestrado em Geografia)- Instituto de Geociências, Universidade Federal do Rio de Janeiro, Rio de Janeiro, 1991.

. Dos espaços da escuridão aos lugares de extrema luminosidade - o universo da estrela Marlene como palco e documento para a construção de conceitos geográficos. 2000. (Doutorado em Geografia) - Instituto de Geociências, Universidade Federal do Rio de Janeiro, Rio de Janeiro, 2000.

MONTEIRO, Carlos Augusto de Figueiredo. O sentimento no mundo entre a ciência (geografia) e a arte (poesia dramática) no nascedouro do Brasil. (Aula Inaugural) São Paulo: SDI/FFLCH/USP, 2005.

MORIN, Edgar. Ciência com consciência. 3. Ed. Rio de Janeiro: Bertrand Brasil, 1999.

NUNES, Benedito. Introdução à filosofia da arte. 3. Ed. São Paulo: Ática, 1991.

NUÑEZ, Carlinda Fragale Pate. Uma Odisséia no espaço: a geografia na literatura. In: ROSENDAHL, Zeny; CORRÊA, Roberto Lobato (org.). Temas e caminhos da geografia cultural. Rio de Janeiro: EdUERJ, 2010, p. 73-113.

OLIVEIRA, Joycelaine Aparecida de; BRANDÃO, Carlos Rodrigues. Entre o murmúrio do rio e o despertar das lembranças. In: RAMIRES, Júlio Cesar de Lima; PESSÔA, Vera Lúcia Salazar (org.). Geografia e pesquisa qualitativa: nas trilhas da investigação. Uberlândia: Assis Ed., 2009, p. 221-252.

ORLANDI, Eni Pulcinelli. Discurso e leitura. 3. Ed. São Paulo e Campinas: Cortez e Ed. UNICAMP, 1996. (Coleção 'Passando a Limpo').

ORTEGA Y GASSET, José. A desumanização da arte. São Paulo: Cortez Ed., 1991. 
PANOFSKY, Erwin. Significado nas artes visuais. 3. Ed. São Paulo: Perspectiva, 2009.

SANTOS, Boaventura de Sousa. Introdução a uma ciência pós-moderna. 4. Ed. Rio de Janeiro: Graal, 1989.

. A crítica da razão indolente: contra o desperdício da experiência. 3. Ed. São Paulo: Cortez Ed., v. 1, 2001.

. Um discurso sobre as ciências. São Paulo: Cortez Ed., 2003.

SILVA, Michel Vieira de Lima e. "Terra prometida ou degredo?” As políticas públicas e a recriação do lugar na Cidade de Deus. 2007. (Especialização em Políticas Territoriais no Estado do Rio de Janeiro) - Instituto de Geografia, Universidade do Estado do Rio de Janeiro, Rio de Janeiro, 2007.

STEINER, Rudolf. Arte e estética segundo Goethe. 2. Ed. São Paulo, Antroposófica, 1998.

TUAN, Yi-Fu. Espaço e Lugar. São Paulo: Difel, 1983.

WANDERLEY, Vernaide. Geografia e poesia do sertão nordestino: uma revisitação às trilhas romanescas de Ariano Suassuna. In: DINIZ, José Alexandre Felizola; FRANÇA, Vera Lúcia Alves (org.). Capitulos de geografia nordestina. Aracajú: NPGEO/UFS, 1998, p. 23-39.

Melissa Anjos

Professora Doutora pelo Programa de Pós-Graduação em Geografia da

Universidade do Estado do Rio de Janeiro (UERJ). Professora associada ao

Núcleo de Estudos em Geografia Humanística, Artes e cidade do Rio de Janeiro

(NeghaRIO) e colaboradora do projeto extensionista da UERJ "Roteiros

Geográficos do Rio".

Rua São Francisco Xavier, 524, Pavilhão João Lyra Filho, $4^{\circ}$ andar, Bloco F, Sala 4006, Maracanã, Rio de Janeiro, CEP 20550-900.

E-mail: melanjos79@gmail.com

Recebido para publicação em fevereiro de 2014 Aprovado para publicação em junho de 2015 